\title{
Physiological and biochemical characteristics of Populus tremula leaves in anthropogenic disturbed habitats
}

\author{
Yulia V. Zagurskaya ${ }^{1, *}$, Tatyana I. Siromlya ${ }^{2}$, Olga V. Kotsupiy ${ }^{3}$, Elena Yu. Babaeva ${ }^{4,5}$, and \\ Vladimir I. Ufimtsev ${ }^{1}$ \\ ${ }^{1}$ Federal Research Center on Coal and Coal Chemistry SB RAS (Institute of Human Ecology), \\ 650065, Kemerovo, Russia \\ ${ }^{2}$ Institute of Soil Science and Agrochemistry SB RAS, 630090, Novosibirsk, Russia \\ ${ }^{3}$ Central Siberian Botanical Garden, SB RAS, 630090, Novosibirsk, Russia \\ ${ }^{4}$ People's Friendship University of Russia, 117198, Moscow, Russia \\ ${ }^{5}$ All-Russian Sci. Research Institute of Medicinal and Aromatic Plants, 117216, Moscow, Russia
}

\begin{abstract}
The main morphological, anatomical, physiological and biochemical characteristics of Populus tremula undergrowth leaves as resistance indicators under conditions of coal pit waste dump are considered. There has been established high variability of morphological parameters and chemical elements composition and anatomical structure peculiarities. There are reported the differences in the content of photosynthetic pigments and phenol compounds.
\end{abstract}

\section{Introduction}

The study of plant resistance and adaptation mechanisms to anthropogenic disturbed habitat conditions is one of the most urgent directions of modern botanic and ecology. The most important objects under study among woody plants are the main forest forming kinds. In Siberia, they are hardwood of Betula and Pópulus including Pópulus trémula [1]. Resistance mechanisms of $P$. tremula to difficult environments and anthropogenic impact are studied insufficiently [2-8].

The goal was to study some biochemical and physiological characteristics of aspen leaves under industrial pollution conditions.

\section{Materials and Methods}

\subsection{Object of study}

The object of the study was Pópulus trémula coenopopulations of 10-15 years on the territory of "Kedrovskiy" coal pit (Kemerovo city) under ontogenesis generative stage

\footnotetext{
* Corresponding author: syjil.extra@gmail.com
} 
(undergrowth). The samples of laminas were collected in the beginning of August 2015 from brachyblasts of different trees at 1.5-2 m height. The experiment plots were: 1) the territory with virgin soil layer without intensive transport stress (control); 2) the overgrowing dump of about 30 years (dump 1); 3) the aspen-reclamated dump of about 30 years with in $50 \mathrm{~m}$ from the dump bank of working pit (dump 2); 4) the technological road border on the coal pit territory with regular traffic of mining technical equipment and largesize diesel transport (road).

\subsection{Physiological and Chemical methods}

The total water content in the leaves and extractive substances amount were determined by gravimetric method [9]. Linear parameters were measured with a ruler (SS 17435). The leaf square was calculated by carving method. Anatomic leaf structure was studied by the methodology reported in State Pharmakopoeia of the RF. XIII ed. (OFS 1.5.1.0003. 15) [9], LOMO Mikmed-1 microscope with AU-12 binoculars of $1.5 \mathrm{x}$ and $1.8 \mathrm{x}$ (ocular 10x, objective lens 10x, 20x and 40x) and MBC 10 binocular as well.

Photosynthetic pigments content was determined by spectrophotometric method [1012], phenol compounds composition and content - by HPLS method [13]. Chemical elements composition was defined after dry ashing by atomic-emission spectroscopy method and accuracy control on the standard samples. Variance analysis was carried out by Kruskal-Wallis method and correlation one - by Spearman method, critical level of p values was taken as 0.05 . All data are given in terms of overdry matter.

\section{Results}

The leaves of aspen brachyblasts were round-shaped (up to 50\%) or egg-shaped (about $20 \%$ ), there were rarely occurred elliptic (rhomb)-shaped, inversely egg-shaped or asymmetric ones; there were not revealed statistically significant differences in lamina shapes. The length (M/Min-Max: 5.2/3.8-7.0 cm), the width (4.9/3.5-6.5 см) and the leaves square (23.3/18.8-31.8 см2) varied significantly but did not differ in depend on habitat either.

The studied samples had similar anatomical characteristics. The cells of abaxial and adaxial leaf epidermis had anfractuose walls. Stomatal apparatus is anomocytic type. Around stomata there was observed cuticle rugosity. Lamina edge was slightly wavy, nervation in mesophill was seen clearly and on the large veins there were occurred prismatic crystals of $\mathrm{CaC} 2 \mathrm{O} 4$ (Fig. 1).

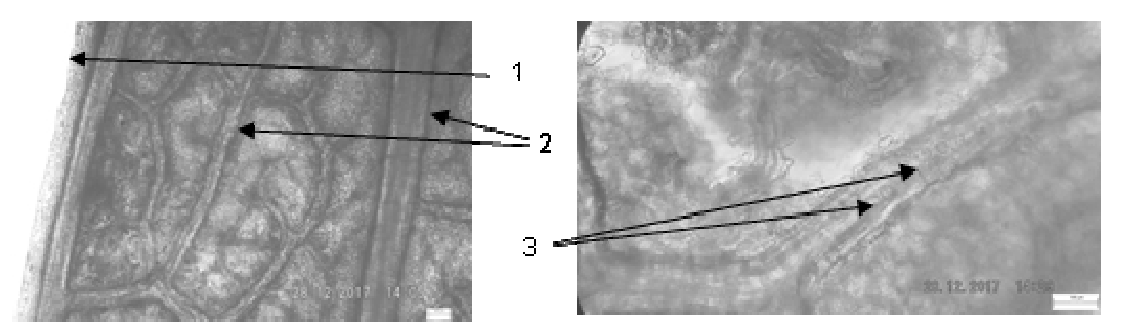

Fig. 1. Characteristics of anatomical structure of aspen leaf (1 - lamina edge (Magnification 450), 2 veins, 3 - crystals of $\mathrm{CaC} 2 \mathrm{O} 4$ on the veins (Magnification 900)).

The total water content in the leaves from different habitats was within 51-59\% that was comparable with the values for the most mesomorphic plants. With anthropogenic stress growing, the extractive substances content, probably, increased due to hydrophilic fraction compounds (Table 1). 
In aqueous-alcoholic extracts of aspen leaves we revealed from 20 to 27 compounds of phenol origin with 4 dominating flavonol glicosides (including hyperoside, rutin and astragaline) and 6 components of phenol carbonic acids (including gallic acid, clorogenic and cinnamic ones).

Table 1. Content of extractive substances, photosynthetic pigments and phenol compounds in aspen leaves $(\mathrm{M} \pm \mathrm{S}), \%$ per overdry weight.

\begin{tabular}{|l|c|c|c|c|}
\hline \multicolumn{1}{|c|}{ Content } & Control & Dump 1 & Dump 2 & Road \\
\hline $\begin{array}{l}\text { Total soluble matters } \\
\text { (acetone) }\end{array}$ & $11,8 \pm 0,5$ & $11,7 \pm 0,4$ & $12,2 \pm 0,3$ & $15,3 \pm 0,8$ \\
\hline $\begin{array}{l}\text { Hydrophilic } \\
\text { compounds }\end{array}$ & $5,9 \pm 0,8$ & $7,5 \pm 0,6$ & $7,4 \pm 0,6$ & $10,4 \pm 0,7$ \\
\hline Chlorophylls & $0,52 \pm 0,06$ & $0,40 \pm 0,03$ & $0,35 \pm 0,04$ & $0,42 \pm 0,03$ \\
\hline Carotenoids & $0,17 \pm 0,02$ & $0,14 \pm 0,01$ & $0,12 \pm 0,01$ & $0,15 \pm 0,01$ \\
\hline Flavonoids & $3,1 \pm 0,2$ & $2,2 \pm 0,2$ & $4,0 \pm 0,2$ & $2,7 \pm 0,2$ \\
\hline Phenolic acids & $0,53 \pm 0,09$ & $0,81 \pm 0,14$ & $1,31 \pm 0,27$ & $1,62 \pm 0,23$ \\
\hline
\end{tabular}

Chemical elements composition of $P$. tremula leaves from disturbed habitats did not differ. While comparing with the samples taken from the control plot, there were not revealed statistically significant difference in the content of the main plant nutrition elements of N, P, K. "Microelements" concentration $(\mathrm{mg} / \mathrm{kg}$ ) also changed within the same values: B (40-170), Co (0.9-1.6), $\mathrm{Cu}$ (5-8), Mo (0.1-0.4) and $\mathrm{Zn}(120-260)$ as well as that of some other chemical elements including "toxic" ones: Sn (0.4-1.2), Cd (0.7-1.9), Ni (2.54.8), Sr (40-170) and Mg (1800-4200) (Fig. 2).

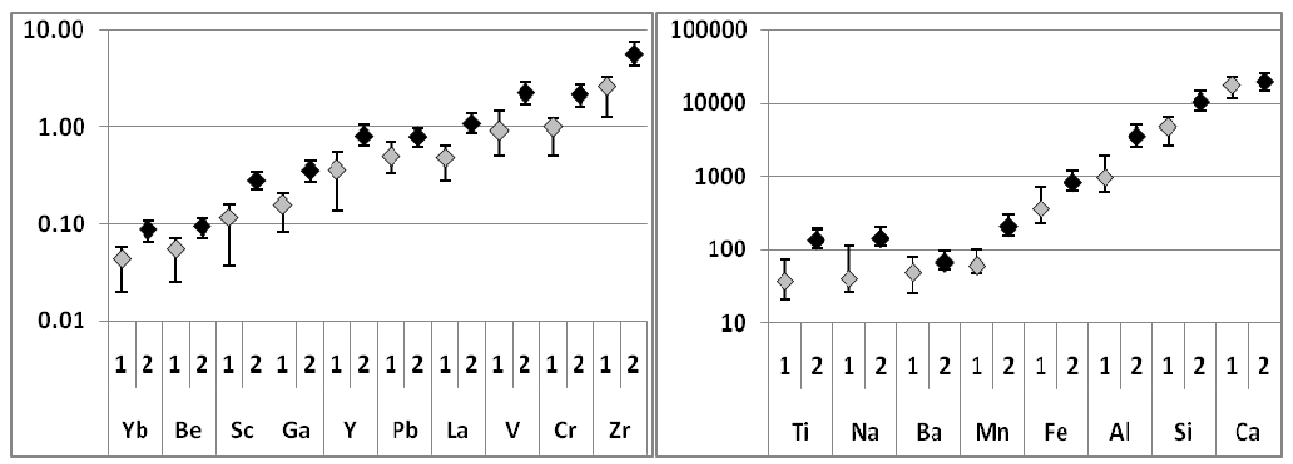

Fig. 2. Content of some chemical elements of $P$. tremula leaves from disturbed habitats, $\mathrm{mg} / \mathrm{kg}(1-$ disturbed ecotopes, 2 - control plot).

\section{Discussion}

The study results of anatomic and morphological characteristics of the aspen undergrowth brachyblasts leaves in the conditions of "Kedrovskiy" coal pit generally correlate with the reported data [14], but they are more variable. The total content of photosynthetic pigments in the aspen leaves from anthropogenically disturbed habitats decreased that confirmed reported information [4-6], besides that, there were observed increasing of pigments share in the amount of substances extracted with weakly polar extractant (acetone) [3].

According to reported data, in the aspen leaves there were revealed more than 20 of phenic compounds, including flavonoids (hyperoside, rutin, quercitrin, isoquercitrin, 
astragalin) and also phenolglicosides; hydroxibenzoic and hydroxicinnamic acids [7, 8 1417]. The peculiarity of phenol compounds composition of anthropogenically disturbed ecotopes was ratio change of hyperoside and rutin dominating flavonoids.

There was revealed direct strong correlation of $\mathrm{rS}-0.75-0.93$ between all chemical elements content being of higher amounts in the plants of the control plot and studied leaves ashing. Increased dust level, probably, was connected with granulometric soil composition; the content of highly dispersed clay fraction reached $45-48 \%$ while on the other plots it did not exceed $3-10 \%$ and was accompanied by a very high rubbliness (30$40 \%$ ) that was specific to immature soils of anthropogenic landscapes [18]. There also has been reported that technogenic pollution impact is not the only significant environmental factor that forms a certain level of biomass chemism as quantity changes depend more on the specific habitat conditions [19]. Chemical elements composition of $P$. tremula in comparison with reported data shows as similarities so differences [20].

\section{References}

1. I.Yu. Koropachinskiy, T.N. Vstovskaya, Woody plants of the Asian part of Russia (Novosibirsk: Publ. House of SB RAS, Branch «Geo», 2002)

2. V.V. Tuzhilkina, Rastit. Resursy 51, 181 (2015)

3. Y.V. Zagurskaya, Reg. Environm. Iss. 1, 24 (2017)

4. Yu.V. Zagurskaya, Sib. J. Forest Sci. 1, 105 (2017)

5. M.V. Tcherkashina, G.A. Petukhova, Adv. Curr. Nat. Sci. 2, 41 (2007)

6. A.A.Rostunov, T.A. Konchina, Bull. Irkutsk St. Univ. Ser.Biol., Ecol. 15, 68 (2016)

7. K. Nissinen, V. Virjamo, T. Randriamanana, N. Sobuj, U. Sivadasan, L. Mehtatalo, E. Beuker, R. Julkunen-Tiitto, L. Nybakken, Canad. J. Forest Res. 47, 1350 (2017)

8. N. Sobuj, V. Virjamo, Y. D. Zhang, L. Nybakken, R. Julkunen-Tiitto, Environm. \& Exp. Bot. 146, 34 (2018)

9. State Pharmakopoeia of the RF. XIII ed. (Moskow, Min. Zdrav. RF, 2015)

10. G. Holm, Acta. Agr. Scand. 4, 457 (1954)

11. D. Wettstein, Exp. Cell Res. 12, 427 (1957)

12. N.V. Shadrin, I.V. Drobetskaya, I.N. Chubchikova, N.V. Terentyeva, Mar. Ekol. J. 7, 85 (2008)

13. O.V. Kotsupiy, G.I. Vysochina, Schol. Not. Transbaikal St. Univ. 11, 104 (2016)

14. Y.V. Banayev, S.V. Shishkin, M.S. Voronkova, A.P. Belanova, M.A. Tomoshevich, Bull. Altai St. Agric. Univ. 8, 90 (2017)

15. E. Häikiö, M. Makkonen, R. Julkunen-Tiitto, J. Sitte, V. Freiwald, T. Silfver, V. Pandey, E. Beuker, T. Holopainen, E. Oksanen, J. Chem. Ecol., 35, 664 (2009)

16. I.Yu. Lobanova, J. Ural Med. Acad. Sci. 35, 67 (2011)

17. I.N. Abreu, M. Ahnlund, T. Moritz, B.R. Albrectsen, J. Chem. Ecol. 37, 857 (2011)

18. V.A. Androkhanov, E.D. Kulyapina, and V.M. Kurachev, Soils of Technogenic Landscapes: Genesis and Evolution (Izd. SO RAN, Novosibirsk, 2004)

19. L.M. Kavelenova, A. Zdetovetskii, A. Ognevenko, Khim. Rastit. Syrya, 3, 85 (2001)

20. R.H. Giniyatullin, Agr. Bull. Urals, 82, 80 (2011) 